\title{
Pulmonary Hamartomas: A Report of 13 Parenchymal and Endobronchial Cases
}

\author{
Gülbanu Horzum Ekinci ${ }^{1}$, Esra Akkütük Öngel ${ }^{1}$, Osman Hacıömeroğlu ${ }^{1}$, \\ Murat Kavas ${ }^{1}$, Ayşe Ersev², Ali Atasalihi ${ }^{3}$, Adnan Yllmaz ${ }^{1}$ \\ ${ }^{1}$ Clinic of Chest Diseases, Süreyyapaşa Chest Diseases and Thoracic Surgery Training and Research Hospital, İstanbul \\ ${ }^{2}$ Clinic of Pathology, Süreyyapaşa Chest Diseases and Thoracic Surgery Training and Research Hospital, İstanbul \\ ${ }^{3}$ Clinic of Chest Surgery, Süreyyapaşa Chest Diseases and Thoracic Surgery Training and Research Hospital, İstanbul
}

\begin{abstract}
Objective: To analyze clinical, radiographic, bronchoscopic, and therapeutic characteristics of a series of patients in whom pulmonary hamartoma had been diagnosed.

Methods: Retrospective review of cases of pulmonary hamartomas diagnosed by biopsy between January 2007 and May 2012 in a tertiary referral hospital in İstanbul, Turkey.

Results: Of the 13 patients with histologically confirmed pulmonary hamartoma, seven were men and six were women (male/female 1.2/1). Their age ranged from 45 to 68 years old. Three patients were asymptomatic. The duration of symptoms ranged from one week to two years. Chest radiograph findings were abnormal in all patients. The lesions were located in the right lung in nine cases, with lower lobe predilection. Among the patients with pulmonary hamartoma, four (30.8\%) had endobronchial hamartoma. Treatment modality was wedge resection in five cases, enucleation in four cases, bronchoscopic procedures in three cases and lobectomy in one case. Follow-up ranged from one month to 54 months. No tumor recurrence was encountered in the follow-up period.

Conclusion: Pulmonary hamartomas are uncommon benign lesions of the lung. They can be parenchymal or endobronchial in location. Parenchyma sparing surgical procedures such as wedge resection or enucleation and bronchoscopic intervention should be preferred in the treatment of pulmonary hamartomas.
\end{abstract}

Keywords: Bronchoscopy, hamartoma, lung tumor, surgery

Received Date: 15.07.2014 Accepted Date: 09.04.2015 Available Online Date: 04.06 .2015

Address for correspondence Gülbanu Horzum Ekinci E-mail: gulbanuh@hotmail.com

(8) This work is licensed under a Creative Commons Attribution-NonCommercia 4.0 International License.

DOI: 10.5152/ejp.2015.09719

-Available online at www.eurasianjpulmonol.com

\section{INTRODUCTION}

Pulmonary hamartoma is a rare benign tumor of the lung, accounting for $3 \%$ of all tumors of the lung (1). The term hamartoma was first introduced by Albrecht in 1904 to describe tumor-like malformations resulting from a presumptive development abnormality. In 1934, Goldsworthy applied this term to benign tumors located in the lung that were predominantly composed of a combination of fat and cartilage (2). According to different autopsy studies, the incidence of pulmonary hamartomas is between $0.025 \%$ and $0.32 \%$ (3). Pulmonary hamartomas are divided into parenchymal, generally asymptomatic and endobronchial, clinically manifesting as a result of tracheobronchial obstruction (4). Endobronchial group account for $1-20 \%$ of all pulmonary hamartomas $(3,4)$. The aim of this study is to analyze clinical, radiographic, bronchoscopic, and therapeutic characteristics of the patients with pulmonary hamartoma.

\section{METHODS}

The study was a retrospective analysis of the patients diagnosed with a histologically proven pulmonary hamartoma between January 2007 and May 2012 in our three clinics. The study included 13 cases with pulmonary hamartoma. The clinical files were analyzed. For each patient, the following data was gathered: age, gender, history of tobacco use, presenting symptoms, co-morbidities, radiographic and bronchoscopic findings, location and size of the lesions, treatment modalities, surgical complications, duration of follow-up, and recurrence. All chest X-ray, computerized tomography (CT) of the thorax and bronchoscopic images were reviewed by one radiologist and one bronchoscopist. To confirm the 
diagnosis of pulmonary hamartoma, the same pathologist reviewed all available histologic slides.

\section{RESULTS}

The present study included 13 patients with pulmonary hamartoma. The lesions were located intraparenchymally in nine of 13 patients (69.2\%) and endobronchially in the remaining four patients $(30.8 \%)$. Seven patients (53.8\%) were male and six patients (46.2\%) were female. The sex ratio (male/female) was 1.2:1 Their mean age ( \pm SD) was $55.5 \pm 7.6$ years ( $45-68$ years). Five of the patients (38.5\%) were older than 60 years. Six patients $(46.2 \%)$ had no smoking history, one patient (7.8\%) was ex-smoker, and six patients $(46.2 \%)$ were smoker. The mean smoking duration was 45.5 pack-years (30-80 years) in six smoker patients. While seven patients (53.8\%) had no co-morbidity, Chronic Obstructive Pulmonary Disease (COPD) was the most frequent comorbidity in our series. Three patients (23.1\%) were asymptomatic at the time of presentation. These patients had parenchymal type of pulmonary hamartoma. The remaining 10 patients (76.9\%) had chest symptoms. The most common symptom was chest pain (six patients) followed by cough (five patients) and dyspnea (five patients). The duration of symptoms ranged from one week to two years. The clinical characteristics of 13 cases with pulmonary hamartoma were given in Table 1.

Chest radiograph findings were abnormal in all patients. In three patients with endobronchial hamartoma, findings on chest radiographs were consistent with pneumonia. Chest radiograph showed atelectasis in the remaining patient. Among nine patients with parenchymal type, the most common manifestation of chest roentgenogram was a solitary pulmonary nodule (seven patients). Chest X-ray revealed mass lesion in one patient and multiple pulmonary nodules in the other patient. Pre-therapeutic thoracic CT scan was performed in all patients. Thoracic CT scan detected calcification in two patients (15.4\%), whereas calcification was not seen in the chest radiograph of any patient. Six patients with parenchymal hamartoma (case no: $3,4,5,6,9$, and 13) had positron emission tomography-computed tomography (PET-CT) examination before treatment. Only two patients (case no: 5 and 9) had high SUV ${ }_{\max }$ value (SUV max $_{\text {max }} 7.1$ and 9.7). CT-guided transthoracic fine needle biopsy was performed in two patients, with negative diagnostic results. Bronchoscopic examination revealed normal appearance in nine patients. In the remaining four patients, bronchoscopy showed an endobronchial tumor. Diagnosis was established by bronchoscopic biopsy in three patients with endobronchial hamartoma and by surgical procedures in 10 patients. The lesions were located in the right lung in nine patients (69.2\%) and were located in the left lung in four patients (30.8\%). There was lower lobe predilection of lesions in our series. Table 2 summarized radiological, bronchoscopic, and therapeutic findings of the patients.

Three patients with endobronchial hamartoma were treated via rigid bronchoscopy. Treatment modalities used to remove the hamartomas during rigid bronchoscopy were cryotherapy $(n=2)$ and rigid forceps $(n=1)$. There was no complication such as life-threatening bleeding, obstruction, or bronchopulmonary fistula after bronchoscopic intervention. One patient with endobronchial hamartoma and nine patients with parenchymal hamartoma were treated via surgery. Hamartomas were removed by wedge resection in five patients and by enucleation in four cases. Remaining one patient underwent lobectomy. Wedge resection was performed through video-assisted thoracoscopic surgery in three patients and thoracotomy in two cases. Enucleations and lobectomy were performed via thoracotomy. Postoperative pneumonia occurred in one patient seven days after operation (case no: 2). The tumor size ranged from $0.5 \mathrm{~cm}$ to $3.6 \mathrm{~cm}$ (mean, $1.9 \mathrm{~cm}$ ). Follow-up bronchoscopy or thoracic CT scan was performed in three and six patients, respectively. Four patients (30.8\%) were lost to follow-up. Follow-up ranged from one month to 54 months. No tumor recurrence was encountered in the follow-up period.

\section{DISCUSSION}

Pulmonary hamartoma, originally considered a developmental malformation, is now classified as a benign neoplasm derived from the

Table 1. The clinical characteristics of 13 cases with pulmonary hamartoma

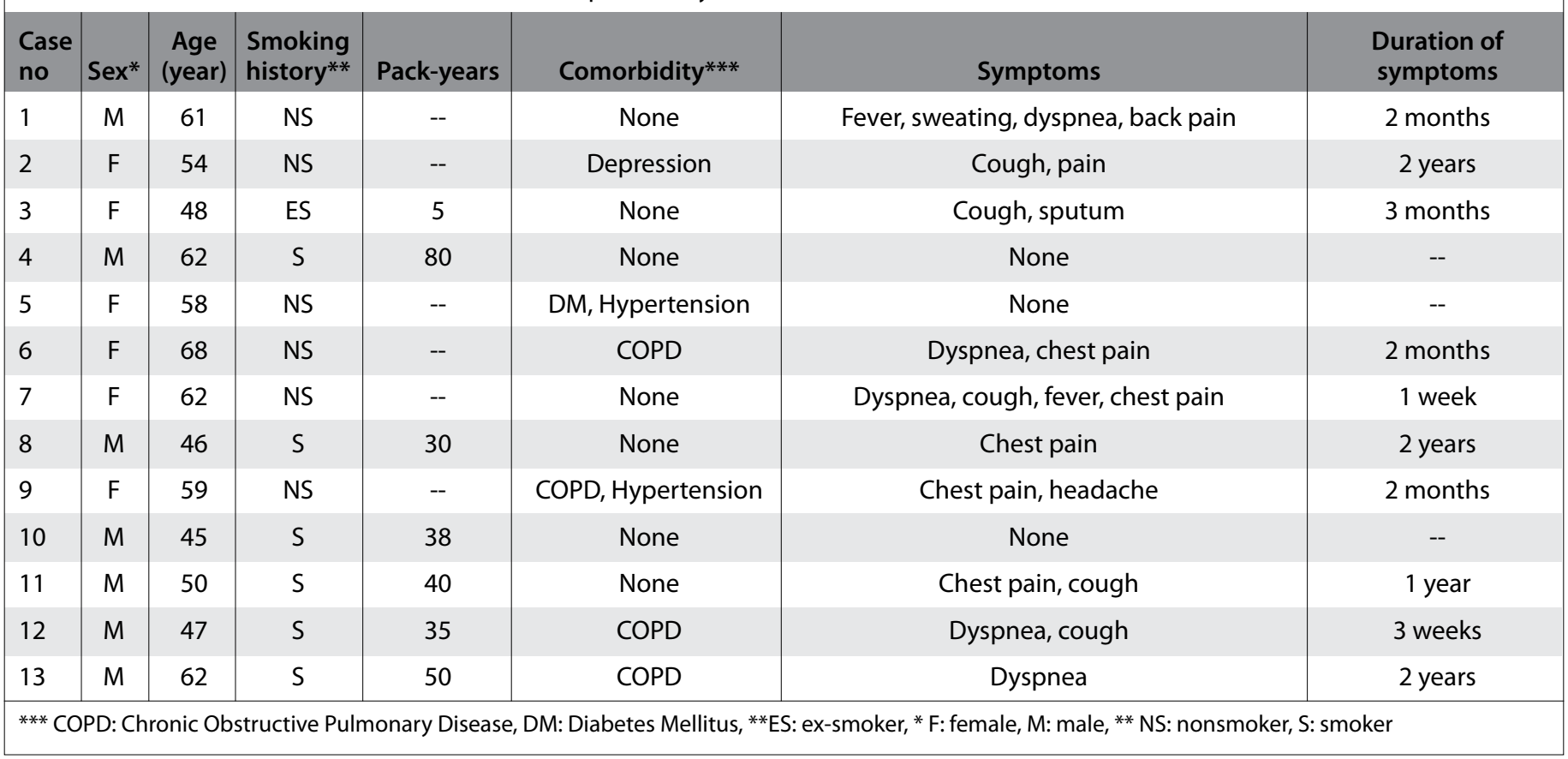


Table 2. The radiological, bronchoscopic, and therapeutic findings of 13 cases with pulmonary hamartoma

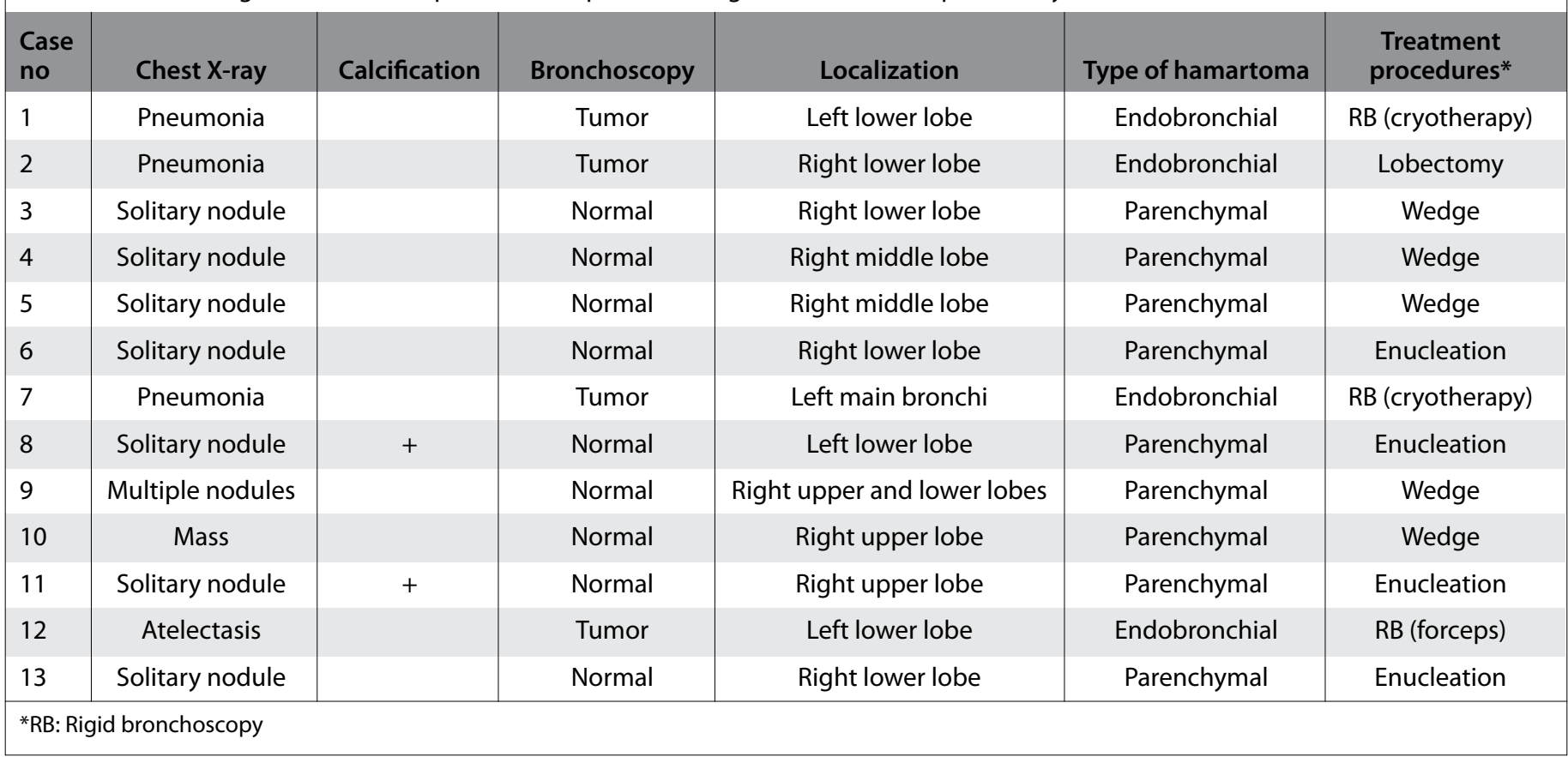

peribronchial mesenchyma (5). Several synonyms have been used for pulmonary hamartoma, including chondromatous hamartoma, hamartochondroma, and mesenchymoma (2). These tumors are predominantly composed of cartilage. Other components include fibromyxoid connective tissue, fat, bone, and smooth muscle (1-5). Most tumors of the tracheabronchial tree are malignant. Among benign lung tumors, hamartomas, with an incidence between $0.025 \%$ and $0.32 \%$, are the most common $(3,4)$.

Pulmonary hamartoma occurs most frequently in middle-aged or elderly patients, and the peak incidence is in the sixth and seventh decade of life. The patients as young as 9 years old and even neonate have been reported in previous series $(2,3)$. Our patients ranged in age from 45 to 68 years and five patients (38.5\%) were in the sixth decade of life, which was consistent with other studies. A greater prevalence of male patients was found in most series, with a variation in male preponderance from 2:1 to 4:1 (1). Our study population included a lower preponderance of male patients. Pulmonary hamartomas can be seen in all parts of the lung, most often in the periphery and rarely near the hilar parts $(1,3)$. They are distributed throughout both lungs. While Guo et al. (1) reported that in terms of the location of the lesions, there was no significant difference between the right and the left lung, Fudge et al. (6) found that the lesions were located in the right lung in 20 of the 29 patients. Two previous studies were reported that all lobes were affected, with a preponderance in the upper lobes $(5,6)$. Gjevre et al. (2) found that the tumors had a slight lower lobe predilection, which is consistent with our study. Pulmonary hamartomas can be parenchymal or endobronchial in location $(4,7,8)$. Endobronchial group account for $1-20 \%$ of all pulmonary hamartomas $(3,4)$, but a higher incidence was found in our series.

Most of the patients with pulmonary hamartoma are free of symptoms at the time of diagnosis, and many are incidentally discovered on chest X-ray examination during assessments for other reasons. However, pulmonary hamartomas can lead to atelectasis, infections, and bleed- ing because of bronchial compression or intraluminal growth (1-4, 7, 8). Gjevre et al. (2) reported that among the 215 patients, only four patients had respiratory complaints attributable to pulmonary hamartoma. On the contrary, Guo et al. (1) found that $76.9 \%$ of the patients with parenchymal hamartoma had chest symptoms such as coughing, expectoration, thoracalgia, and hemoptysis. It was reported that there were respiratory symptoms in 13 of 17 patients with endobronchial hamartoma, the most common of which was a cough (4). According to the other study, one third of their patients had pulmonary symptoms and all of the patients with endobronchial hamartoma were symptomatic (3). In our experience, only three patients (23.1\%) with parenchymal type had no pulmonary symptoms. All patients with endobronchial type were symptomatic. The most common symptom was chest pain followed by cough and dyspnea.

Findings on chest radiograph vary according to size and location of the tumor (7). Chest X-ray findings can be normal or abnormal $(4,5$, 7, 8); Fudge et al. (6) reported that findings on chest X-ray of all patients were abnormal. On chest $\mathrm{X}$-ray examination, a parenchymal hamartoma usually shows up a solitary pulmonary nodule, sometimes with calcification (3). Multiple nodules or a mass lesion can be seen on chest radiographs $(1,3)$. Endobronchial lesions may not be visible themselves, but conventional radiography may show postobstructive changes such as pneumonia, atelectasis, or lung abcess $(7,9)$. Chest radiograph findings were abnormal in all our patients. In three patients with endobronchial hamartoma, findings on chest radiographs were consistent with pneumonia. Chest radiograph showed atelectasis in the remaining patient. Among nine patients with parenchymal type, the most common manifestation of chest X-ray was a solitary pulmonary nodule (seven patients). Chest $X$-ray revealed mass lesion in one patient and multiple pulmonary nodules in the other patient. Characteristics CT findings include a lesion with a smooth edge, focal collection of fat, or collections of fat alternating with foci of calcification. It also shows the parenchymal changes beyond the obstruction $(9,10)$. Calcification and areas of focal fat in the lesion, the diagnostic 
CT findings of pulmonary hamartoma, are found in only $12.5 \%$ of the patients (4). In our series, although focal collection of fat was not seen in thoracic CT scan of any patient, thoracic CT scan detected calcification in two patients (15.4\%).

Pathologic diagnosis of pulmonary hamartomas can be obtained surgical or preoperative methods such as bronchoscopy or transthoracic needle biopsy $(3,8,11,12)$. Bini et al. (11) reported that transthoracic fine needle aspiration biopsy did not establish diagnosis in their case. Hansen et al. (12) observed that preoperative diagnosis from transthoracic needle aspiration could be obtained in $85 \%$ of the patients with pulmonary hamartoma. Bronchoscopic forceps biopsies may especially be diagnostic in patients with endobronchial hamartoma $(4,8)$. In our series, diagnosis was established by bronchoscopic biopsy in three patients with endobronchial hamartoma and by surgical procedures in the remaining 10 patients.

The management of pulmonary hamartomas must be individualized according to the characteristics of each patient and each hamartoma (8). Even with the advances in medical therapy, bronchoscopic interventions and surgical methods currently remain the most important treatment modalities in patients with pulmonary hamartoma $(3,4$, $7,8,13-15)$. However, indication and timing of surgery are still controversial. Since most pulmonary hamartomas are nonexpanding or slowly growing neoplasms, some authors believed that surgery is necessary only when expansion is recorded in young or middle aged patients or accompanying obvious pulmonary symptoms (1, $6,8)$. According to Guo et al. (1), the pulmonary hamartomas have the tendency of expansion or recurrence, and chronic inflammatory stimulation of local position may contribute to the development of malignancy. Therefore, when a solitary pulmonary lesion is more than $2.5 \mathrm{~cm}$ or the possibility of malignancy cannot be excluded, surgical resection should be mandatorily performed. The pulmonary hamartomas are removed by wedge resection or enucleation of the tumor $(1,3,5)$. Only the tumors located deeply in the parenchyma or endobronchial lesions necessitate more extensive procedures such as lobectomy or pneumonectomy $(3,5)$. Bronchoscopic procedures such as rigid forceps, laser resection, cryotherapy, and snaring are safe and effective therapeutic options for selected patients with endobronchial hamartoma (4, 13-15). In our experience, three of four endobronchal hamartomas were treated via bronchoscopic procedures. All of the parenchymal hamartomas were removed by wedge resection or enucleation of the tumor. Only one patient with endobronchial hamartoma underwent lobectomy. No tumor recurrence was encountered in the follow-up period.

Although hamartoma is generally considered to be a benign neoplasm, there are several reports of increased risk for lung cancer in patients with hamartoma $(1,2,5,7,8)$. According to Van den Bosch et al. (5) series, $7 \%$ of their patients had synchronous or metachronous bronchial carcinoma. Fudge et al. (6) found that there were symptoms related to concomitant malignancy in $20 \%$ of the patients. Malignant change in benign pulmonary hamartoma is well known $(16,17)$. In our series, there was no synchronous malignancy or malignant change in hamartoma.

\section{CONCLUSION}

Pulmonary hamartomas are uncommon benign lesions of the lung. They can be parenchymal or endobronchial in location. Parenchymal sparing surgical procedures, such as wedge resection or enucleation or bronchoscopic interventions, should be preferred in the treatment of pulmonary hamartomas.

Ethics Committee Approval: Study done by retrospective data analyses so ethics commitee approval was not taken.

Informed Consent: Due to the retrospective design of the study, informed consent was not taken.

Peer-review: Externally peer-reviewed.

Author contributions: Concept - G.H.E., E.A.Ö., O.H., M.K., A.E., A.A., A.Y.; Design - G.H.E., E.A.Ö., O.H., M.K., A.E., A.A., A.Y.; Supervision - G.H.E., E.A.Ö., E.H., A.E., A.A., A.Y.; Funding - A.Y.; Materials - A.E., A.A.; Data Collection and/or Processing - A.Y., G.H.E., O.H., M.K., E.A.Ö.; Analysis and/or Interpretation - A.Y., G.H.E., O.H., M.K.; Literature Search - A.Y., E.A.Ö.; Writing - A.Y., G.H.E., O.H.; Critical Reviews - O.H., G.H.E., A.Y., M.K.

Conflict of Interest: No conflict of interest was declared by the authors.

Financial Disclosure: The authors declared that this study has received no financial support.

\section{REFERENCES}

1. Guo W, Zhao YP, Hang YG, Wang RW, Ma Z. Surgical treatment and outcome of pulmonary hamartoma: a retrospective study of 20-year experience. J Exp Clin Cancer Res 2008; 27: 8. [CrossRef]

2. Gjevre JA, Myers JL, Prakash UB. Pulmonary hamartomas. Mayo Clin Proc 1996; 71: 14-20. [CrossRef]

3. Lien YC, Hsu HS, Li WY, Wu YC, Hsu WH, Wang LS, et al. Pulmonary hamartoma. J Chin Med Assoc 2004; 67: 21-6.

4. Kim SA, Um SW, Song JU, Jeon K, Koh WJ, Suh GY, et al. Bronchoscopic features and bronchoscopic intervention for endobronchial hamartoma. Respirology 2010; 15: 150-4. [CrossRef]

5. Van den Bosch JM, Wagenaar SS, Corrin B, Elbers JR, Knaepen PJ, Westermann CJJ. Mesenchymoma of the lung (so called hamartoma): a review of 154 parenchymal and endobronchial cases. Thorax 1987; 42: 790-3. [CrossRef]

6. Fudge TL, Ochsner JL, Mills NL. Clinical spectrum of pulmonary hamartomas. Ann Thorac Surg 1980; 30: 36-9. [CrossRef]

7. Lazovic B, Jakovic R, Dubajic S, Gataric Z. Pulmonary hamartoma- case report and review of literature. Arch Oncol 2011; 19: 37-8. [CrossRef]

8. Cosio BG, Villena V, Echave-Sustaeta J, de Miguel E, Alfaro J, Hernandez L, et al. Endobronchial hamartoma. Chest 2002; 122: 202-5. [CrossRef]

9. Yilmaz S, Ekici A, Erdogan S, Ekici M. Endobronchial lipomatous hamartoma: CT and MR imaging features. Eur Radiol 2004; 14: 1521-4.

10. Karabulut N, Bir F, Yuncu G, Kiter G. Endobronchial lipomatous hamartoma: an unusual cause of bronchial obstruction. Eur Radiol 2007; 17: 2687-90. [CrossRef]

11. Bini A, Grazia M, Petrella F, Chittolini M. Multiple chondromatous hamartomas of the lung. Interact Cardiovasc Thorac Surg 2002; 1: 78-80. [CrossRef]

12. Hansen $C P$, Holtveg $H$, Francis $D$, Rasch $L$, Bertelsen $S$. Pulmonary hamartoma. J Thorac Cardiovasc Surg 1992; 104: 674-8.

13. Rai SP, Patil AP, Saxena P, Kaur A. Laser resection of endobronchial hamartoma via fiberoptic bronchoscopy. Lung India 2010; 27: 170-2. [CrossRef]

14. Lee SH, Kim KT, Yi EJ, Son JS. Endoscoopic cryosurgical resection of pulmonary hamartoma with flexible bronchoscopy. Korean JThorac Cardiovasc Surg 2011; 44: 307-10. [CrossRef]

15. Mondello B, Lentini S, Buda C, Monaco F, Familiari D, Sibilio M, et al. Giant endobronchial hamartoma resected by fiberoptic bronchoscopy electrosurgical snaring. J Cardiothorac Surg 2011; 6: 97. [CrossRef]

16. Poulsen JT, Jacobsen M, Francis D. Probable malignant transformation of a pulmonary hamartoma. Thorax 1979; 34: 557-8. [CrossRef]

17. Basile A, Gregoris A, Antoci B, Romanelli M. Malignant change in a benign pulmonary hamartoma. Thorax 1989; 44: 232-3. [CrossRef] 